\title{
Radiation and Mass Transfer Effects on Transient Free Convection Flow of a Dissipative Fluid past Semi-Infinite Vertical Plate with Uniform Heat and Mass Flux
}

\author{
B.Vasu ${ }^{1}$, V. Ramachandra Prasad ${ }^{2} *$ and N. Bhaskar Reddy ${ }^{3}$ \\ ${ }^{I}$ Department of Mathematics, $S$ V University, Tirupati 517502, India \\ ${ }^{2}$ Department of Mathematics, Madanapalle Institute of Technology and Science, \\ Madanapalle, 517325, India \\ ${ }^{3}$ Department of Mathematics, S V University, Tirupati 517502, India \\ *Email: rcpmaths@mits.ac.in
}

(Received February 12, 2009; accepted August 12, 2009)

\begin{abstract}
Effect of radiation and mass transfer on the transient free convection flow of a dissipative past semi-infinite vertical plate with uniform heat and mass flux is analyzed, by taking into account the effect of viscous dissipation. This type of problems finds application in many technological and engineering fields such as plasma studies, petroleum industries, MHD energy generators, cooling of nuclear reactors, the boundary layer control in aerodynamics, crystal growth and furnace engineering. The Rosseland approximation is used to describe the radiative heat transfer in the limit of the optically thick fluid. The non-linear, coupled equations are solved using an implicit finite difference scheme of Crank-Nicolson type. Transient temperature, concentration and velocity profiles, local and average skinfriction coefficient, Nusselt number and Sherwood number are presented graphically and discussed. It is observed that, when the radiation parameter increases the velocity and temperature decrease accompanied by simultaneous reduction in both momentum and thermal boundary layers.
\end{abstract}

Keywords: Steady, Boundary Layer, MHD, Radiation, Heat and mass transfer, viscous dissipation.

\section{NOMENCLATURE}

$\begin{array}{ll}C^{\prime} & \begin{array}{l}\text { species concentration in fluid } \\ C_{\infty}^{\prime}\end{array} \\ & \begin{array}{l}\text { species concentration in fluid for away from } \\ \text { the plate }\end{array} \\ C_{w}^{\prime} & \begin{array}{l}\text { species concentration at the plate } \\ \text { non-dimensional species concentration }\end{array} \\ C^{\prime} & \text { specific heat at constant pressure } \\ C_{p} & \text { the species diffusion coefficient } \\ \mathrm{D} & \text { dissipation parameter } \\ \mathrm{Ec} & \text { radiation parameter } \\ \mathrm{F} & \text { thermal Grashof number } \\ \mathrm{Gr} & \text { acceleration due to gravity } \\ \mathrm{g} & \text { the thermal conductivity } \\ \mathrm{k} & \text { length of the plate } \\ \mathrm{L} & \text { magnetic parameter } \\ \mathrm{M} & \text { buoyancy ratio parameter } \\ \mathrm{N} & \text { dimensionless local Nusselt number } \\ \mathrm{Nu}_{X} & \text { dimensionless average Nusselt number } \\ \overline{N u} & \text { prandtl number } \\ \mathrm{Pr} & \text { heat flux per unit area at the plate } \\ \mathrm{q} & \end{array}$

\begin{tabular}{|c|c|}
\hline $\mathrm{q}_{\mathrm{r}}$ & radiativeheat flux \\
\hline$q_{w}^{*}$ & mass flux per unit area \\
\hline $\mathrm{Sc}$ & Schmidt number \\
\hline$S h_{X}$ & dimensionless local Sherwood number \\
\hline$\overline{S h}$ & dimensionless average Sherwood number \\
\hline$T$ & dimensionless temperature \\
\hline$T^{\prime}$ & temperature of the fluid \\
\hline$T_{\infty}^{\prime}$ & $\begin{array}{l}\text { temperature of the fluid far away from the } \\
\text { plate }\end{array}$ \\
\hline$T_{w}^{\prime}$ & the wall temperature \\
\hline$t$ & dimensionless time \\
\hline$t^{\prime}$ & time \\
\hline $\mathrm{u}, \mathrm{v}$ & $\begin{array}{l}\text { velocity components in the } \mathrm{x} \text { and } \mathrm{y} \text { directions } \\
\text { respectively }\end{array}$ \\
\hline $\mathrm{U}, \mathrm{V}$ & $\begin{array}{l}\text { dimensionless velocity components in the } \mathrm{x} \\
\text { and y directions respectively }\end{array}$ \\
\hline x & spatial coordinate along the plate \\
\hline
\end{tabular}


$\mathrm{X}$

dimensionless spatial coordinate along the plate

y spatial coordinate normal to the plate

Y dimensionless spatial coordinate normal to the plate

\section{Greek Symbols:}

$\alpha \quad$ thermal diffusivity

$\beta \quad$ volumetric coefficient of thermal expansion

\section{INTRODUCTION}

Steady free convection flow of incompressible viscous fluid past an infinite or semi-infinite vertical plate is studied since long because of its technological importance. Pohlhausen (1921) was the first to study it for a flow past or semi- infinite vertical plate by integral method. Similarity solution to this problem was given by Ostrach (1953). Siegel (1958) studied the transient free convective flow past a semi- infinite vertical plate by integral method. The same problem was studied by Gebhart (1961) by an approximate method.

The study of magneto-hydrodynamic flow for electrically conducting fluid past heated surface has attracted the interest of many researches in view of its important applications in many engineering problems such as plasma studies, petroleum industries MHD power generations, cooling of nuclear reactors, the boundary layer control in aerodynamics and crystal growth. Until recently this study has been largely concerned with flow and heat transfer characteristics in various physical situations. Watanabe and Pop (1994) investigated the heat transfer in the thermal boundary layer of magneto-hydrodynamic flow over a flat plate. Michiyochi et al. (1976) considered natural convection heat transfer from a horizontal cylinder to the mercury under a magnetic field. Vajravelu and Nayfeh (1992) studied hydro magnetic convection at a cone and a wedge. The study of magnetic-hydrodynamic free convection through a viscous fluid past a semi- infinite plate is considered very essential to understand the behavior of the performance of the fluid motion in several applications. It serves as the basis for understanding some of the important phenomena occurring in heat exchange devices. MHD free convection flows past a semi- infinite vertical plate have been studied in different physical condition by Sparrow and Cess (1961), Riley (1976) and others.

The Problems mentioned above are concerned with thermal convection only. But in nature along with free convection currents caused by the temperature differences, the flow is also affected by the differences in material constitution, for example, in atmospheric flows there exist differences in $\mathrm{H}_{2} \mathrm{O}$ concentration and hence the flow is affected by such concentration difference. In many engineering applications, the foreign gases are injected. This causes a reduction in wall shear stress, the mass transfer conductance or the rate of heat transfer. Usually, $\mathrm{H}_{2} \mathrm{O}, \mathrm{CO}_{2}$, etc are the foreign gases, which are injected in the air flowing past bodies. The effects of foreign mass, also known as diffusing species concentration were studied under

$\begin{array}{ll}\beta^{*} & \begin{array}{l}\text { volumetric coefficient of thermal expansion } \\ \text { with concentration }\end{array} \\ \sigma & \text { electrical conductivity } \\ \mu & \text { dynamic viscosity } \\ v & \text { kinematic viscosity } \\ \rho & \text { density } \\ { }^{\prime} X & \text { dimensional local skin-friction } \\ \bar{\tau} & \text { dimensional average skin-friction }\end{array}$

different conditions by Somers (1956), Mathers et al. (1956), and others either by integral method or by asymptotic analysis. But the first systematic study of mass transfer effects on free convection flow past a semi infinite vertical plate was presented by Gebhart and Pera (1971) who presented a similarity solution to this problem and introduced a parameter $\mathrm{N}$ which is a measure of relative importance of chemical and thermal diffusion causing a density difference that drives the flow the parameter $\mathrm{N}$ is positive when both effects combined to drive the flow and it is negative when these effects are opposed. Unsteady free convective flow on taking into account the mass transfer phenomenon past an infinite vertical porous plate with constant suction was studied by Soundalgekar and Wavre (1977). Callahan and Manner (1976) first considered the transient free convection flow past a semi infinite plate by explicit finite difference method. They also considered the presence of species concentration. However this analysis is not applicable for other fluids whose Prandtl number is different from unity. Soundalgekar and Ganesan (1981) analyzed transient free convective flow past a semi infinite vertical flat plate, taking into account mass transfer by an implicit finite difference method of Crank-Nicolson type. In their analysis they observed that an increase in the $\mathrm{N}$ leads to an increase in the velocity but a decrease in the temperature and concentration. Elbashbeshy (1997) studied heat and mass transfer along a vertical plate with variable surface temperature and concentration in the presence of magnetic field. Aboeldahab and Elbarbary (2001) took into account the Hall current effect on the MHD free convection heat and mass transfer over a semi infinite vertical plate upon which the flow subjected to a strong external magnetic field. Chen (2004) studied heat and mass transfer in MHD flow by natural convection from a permeable inclined surface with variable temperature and concentration using Keller box finite difference method and found that an increase in the value of temperature exponent $\mathrm{m}$ leads to a decrease in the local skin friction, Nusselt and Sherwood numbers. Takhar et al. (1997) considered the unsteady free convection flow over a semi infinite vertical plate. Ganesan and Rani (2000) studied the unsteady free convection on vertical cylinder with variable heat and mass flux.

Heat transfer by simultaneous radiation and convection has applications in numerous technological problems, including combustion, furnace design, the design of high temperature gas cooled nuclear reactors, nuclear reactor safety, fluidized bed heat exchanger, fire spreads, advance energy conversion devices such as open cycle coal and natural gas fired MHD, solar fans, 
solar collectors natural convection in cavities, turbid water bodies, photo chemical reactors and many others when heat transfer by radiation is of the same order of magnitude as by convection, a separate calculation of radiation and convection and their superposition without considering the interaction between them can lead to significant errors in the results, because of the presence of the radiation in the medium, which alters the temperature distribution within the fluid. Therefore, in such situation heat transfer by convection and radiation should be solved for simultaneously. In this context, Abd El-Naby et al. (2003) studied the effects of radiation on unsteady free convective flow past a semi infinite vertical plate with variable surface temperature using Crank-Nicolson finite difference method. They observed that, both the velocity and temperature are found to decrease with an increase in the temperature exponent. Chamkha et al. (2001) analyzed the effects of radiation on free convection flow past a semi-infinite vertical plate with mass transfer by taking into account the buoyancy ratio parameter N. In their analysis they found that, as the distance from the leading edge increase, both the velocity and temperature decrease, where as the concentration increases. Ganesan and Loganadhan (2002) studied the radiation and mass transfer effects on flow of incompressible viscous fluid past a moving vertical cylinder using Resseland approximation by The Crank-Nicolson finite difference method. Takhar et al. (1996) considered the effects of radiation on MHD free convection flow of a radiating gas past a semi infinite vertical plate.

In most of the studies mentioned above, viscous dissipation is neglected. Gebhart (1962) has shown the importance of viscous dissipative heat in free convection flow along a semi infinite vertical isothermal plate and presented similarity solution by a defining a dissipation parameter $E c=\frac{g \beta L}{C p}$, which is the ratio of kinetic energy of the flow to the heat transformed to the fluid. Gebhart and Mollendorf (1969) considered the effects of viscous dissipation for external natural convection flow over a surface. Soundalgekar (1972) analyzed viscous dissipative heat on the two dimensional unsteady flow past an infinite vertical porous plate when the temperature oscillates in time there is constant suction on the plate. IsraelCookey et al. (2003) investigated the influence of viscous dissipation and radiation on MHD free convection flow past an infinite heated vertical plate in a porous medium with time dependent suction. Gokhale and Samman (2003) studied the effects of mass transfer on the transient free convection flow of a dissipative fluid along a semi infinite vertical plate with constant heat flux.

The aim of the present chapter is to study the thermal radiation effects on unsteady two dimensional hydro magnetic free convection flow of a viscous, incompressible fluid, past the semi infinite vertical plate with uniform heat and mass flux taking to account the effects of viscous dissipation. The equations of continuity, linear momentum, energy and diffusion, which governed flow field, are solved by using an implicit finite difference method of Crank - Nicolson type.

The behavior of the velocity, temperature concentration skin friction, Nusselt and Sherwood numbers have been discussed for variations in governing parameters.

\section{Mathematical Analysis}

Consider a two dimensional transient hydro-magnetic laminar natural convection flow of a viscous, incompressible radiating fluid past a semi infinite vertical plate, taking into account the effect of viscous dissipation is considered. The $\mathrm{x}$-axis is taken along the plate in the vertically upward direction, and the y-axis is taken normal to the plate. Initially, it is assumed that the plate and the fluid are at the same temperature $T_{\infty}^{\prime}$ and the concentration level $C_{\infty}^{\prime}$ everywhere in the fluid. Time $t^{\prime}>0$, the temperature and the concentration level near the plate are raised at the constant rate. It is assumed that the concentration $C^{\prime}$ of the diffusing species in the binary mixture is very less in comparison to the other chemical species, which represent and hence the Soret and Dufour effects are negligible then, under the above assumption, the governing boundary layer equations with Boussinesq's approximation are

$$
\begin{aligned}
& \frac{\partial u}{\partial x}+\frac{\partial v}{\partial y}=0 \\
& \begin{aligned}
\frac{\partial u}{\partial t^{\prime}}+u \frac{\partial u}{\partial x}+v \frac{\partial u}{\partial y}= & v \frac{\partial^{2} u}{\partial y^{2}}+g \beta\left(T^{\prime}-T_{\infty}^{\prime}\right)+ \\
& g \beta *\left(C^{\prime}-C_{\infty}^{\prime}\right)-\frac{\sigma \beta_{0}{ }^{2}}{\rho} u
\end{aligned}
\end{aligned}
$$

$$
\begin{aligned}
\frac{\partial T^{\prime}}{\partial t^{\prime}}+u \frac{\partial T^{\prime}}{\partial x}+v \frac{\partial T^{\prime}}{\partial y}= & \alpha \frac{\partial^{2} T^{\prime}}{\partial y^{2}}+ \\
& \frac{\mu}{\rho c_{p}}\left(\frac{\partial u}{\partial y}\right)^{2}-\frac{1}{\rho c_{p}} \frac{\partial q_{r}}{\partial y}
\end{aligned}
$$

$\frac{\partial C^{\prime}}{\partial t^{\prime}}+u \frac{\partial C^{\prime}}{\partial x}+v \frac{\partial C^{\prime}}{\partial y}=D \frac{\partial^{2} C^{\prime}}{\partial y^{2}}$

The initial and boundary conditions are

$$
\begin{aligned}
& t^{\prime} \leq 0, u=0, v=0, T^{\prime}=T_{\infty}^{\prime}, C^{\prime}=C_{\infty}^{\prime} \text { For all } \mathrm{y} \\
& t^{\prime}>0, u=0, v=0, T^{\prime}=T_{\infty}^{\prime}, C^{\prime}=C_{\infty}^{\prime} \text { at } x=0 \\
& u=0, v=0, \frac{\partial T^{\prime}}{\partial y}=\frac{-q}{k}, C=\frac{-q_{w} *(x)}{D} \text { at } y=0 \\
& u=0, T^{\prime} \rightarrow T_{\infty}^{\prime}, C^{\prime} \rightarrow C_{\infty}^{\prime} \text { as } y \rightarrow \infty
\end{aligned}
$$

Where $\mathrm{u}, \mathrm{v}$ are velocity components in $\mathrm{x}, \mathrm{y}$ directions respectively, $t^{\prime}$ - the time, $\mathrm{g}-$ the acceleration due to gravity, $\beta$ - the volumetric coefficient of thermal expansion, $\beta^{*}$ - the volumetric coefficient of expansion with concentration, $T^{\prime}$ - temperature of the fluid in the 
boundary layer, $C^{\prime}-$ the species concentration in the boundary layer, $T_{w}{ }^{\prime}$ - the wall temperature, $T_{\infty}^{\prime}$ - the temperature of the fluid far away from the plate, $C_{W}^{\prime}$ the concentration at the plate, $C_{\infty}^{\prime}$ - the species concentration in fluid for way from the plate $\sigma$ - the electrical conductivity, $\beta_{0}$ - the magnetic induction, $\rho$ - the density of the fluid, $\alpha$-thermal diffusivity, $k-$ the thermal conductivity, $v$ - the Kinematics viscosity, $C_{p}$ - the specific heat at constant pressure, $q_{r}$ - the radiation heat flux and $\mathrm{D}$ - the species diffusion coefficient.

The third term on the right hand side of the Eq. (3) is the radiative heat flux term. The second term is the viscous dissipation term.

By using Rosseland approximation (Brewster, 1992) the radiative, heat flux $q_{r}$ is given by.

$q_{r}=-\frac{4 \sigma_{s}}{3 k_{e}} \frac{\partial \mathrm{T}^{\prime^{4}}}{\partial y}$

Where $\sigma_{s}$ is the Stefan Boltzmann constant and $k_{e}$ the mean absorption coefficient. It should be noted that by using the Rosseland approximation the present analysis is limited to optically thick fluids. It temperature differences within the flow are sufficiently small, then Eq. (6) can be linearized by expanding $\mathrm{T}^{\prime 4}$ into the Taylor series about $T_{\infty}^{\prime}$, which after neglecting higher order terms takes the form.

$$
\mathrm{T}^{{ }^{4}} \cong 4 T_{\infty}^{\prime^{3}} T^{\prime}-3 T_{\infty}^{\prime^{4}}
$$

In the view of Eqs. (6) and (7), Eq. (3) reduces to

$$
\begin{aligned}
\frac{\partial T^{\prime}}{\partial t^{\prime}}+u \frac{\partial T^{\prime}}{\partial x}+v \frac{\partial T^{\prime}}{\partial y} & =\left[\frac{k}{\rho c_{p}}+\frac{16 \sigma_{s} T_{\infty}^{\prime^{3}}}{3 k_{e} \rho c_{p}}\right] \frac{\partial^{2} T^{\prime}}{\partial y^{2}} \\
& +\frac{v}{c_{p}}\left(\frac{\partial u}{\partial y}\right)^{2}
\end{aligned}
$$

In order to write the governing equations and the boundary conditions in dimensionless form, the following non dimensional quantities are introduced.

$$
\begin{aligned}
& U=\frac{u L}{v G r^{1 / 2}} ; V=\frac{v L}{v G r^{1 / 4}} ; \operatorname{Pr}=\frac{v}{\alpha} ; X=\frac{x}{L} ; \\
& T=\frac{T^{\prime}-T_{\infty}^{\prime}}{\frac{q L}{k G r^{1 / 4}}} ; Y=\frac{y}{L G r^{\frac{-1}{4}}} ; C=\frac{C^{\prime}-C_{\infty}^{\prime}}{\frac{q_{w}^{*} L}{D G r^{1 / 4}}} \\
& G r=\frac{g \beta L^{4} q}{k v^{2}} ; S c=\frac{v}{D} ; F=\frac{k_{e} k}{4 \sigma_{s} T_{\infty}^{\prime 3}} ; \\
& E c=\frac{g \beta L}{C_{p}} ; N=\frac{g \beta^{*} q_{w}^{*} L^{4}}{D G r^{5 / 4} v^{2}} ; t=\frac{t^{\prime} v G r^{1 / 2}}{L^{2}}
\end{aligned}
$$

Equations (1), (2), (8) and (4) are reduced to the following non dimensional form,

$\frac{\partial U}{\partial X}+\frac{\partial V}{\partial Y}=0$

$\frac{\partial U}{\partial t}+U \frac{\partial U}{\partial X}+V \frac{\partial U}{\partial Y}=\frac{\partial^{2} U}{\partial Y^{2}}+T G r^{-1 / 4}$

$\frac{\partial T}{\partial t}+U \frac{\partial T}{\partial X}+V \frac{\partial T}{\partial Y}=\frac{1}{\operatorname{Pr}}\left[1+\frac{4}{3 F}\right] \frac{\partial^{2} T}{\partial Y^{2}}$

$$
\begin{array}{r}
+G r^{1 / 4} E c\left(\frac{\partial U}{\partial Y}\right)^{2} \\
\frac{\partial C}{\partial t}+U \frac{\partial C}{\partial X}+V \frac{\partial C}{\partial Y}=\frac{1}{S c} \frac{\partial^{2} C}{\partial Y^{2}}
\end{array}
$$

The corresponding initial and boundary conditions in non dimensional form are,

$t \leq 0, \quad \mathrm{U}=0, \mathrm{~V}=0, \mathrm{~T}=0, \quad \mathrm{C}=0$

$\mathrm{t}>0, \quad \mathrm{U}=0, \mathrm{~V}=0, \mathrm{~T}=0, \mathrm{C}=0$, at $\mathrm{X}=0$

$\mathrm{U}=0, \mathrm{~V}=0 ; \frac{\partial T}{\partial Y}=-1 ; \frac{\partial C}{\partial Y}=-1$ at $\mathrm{Y}=0$

$\mathrm{U}=0, \mathrm{~T}=0, \mathrm{C}=0$ as $Y \rightarrow \infty$

where L- is the length of the plate, Gr- the Grashof number, Pr- the Prandtl number, Sc- the Schmidt number, F-the radiation parameter, $\mathrm{N}$-the buoyancy ratio parameter and $\mathrm{M}$-the magnetic parameter.

Knowing the velocity, temperature and concentration fields, it is interesting to find the Skin friction, Nusselt number and Sherwood numbers. Following (15-20), these are defined as follows,

Local and average Skin-friction in non -dimensional form is

$$
\begin{aligned}
& \tau_{X}=G r^{3 / 4}\left(\frac{\partial U}{\partial Y}\right)_{Y=0} \\
& \bar{\tau}=G r^{3 / 4} \int_{0}^{1}\left(\frac{\partial U}{\partial Y}\right)_{Y=0} d X
\end{aligned}
$$

Local and average Nusselt numbers in non-dimensional form are

$$
\begin{aligned}
& N u_{X}=G r^{1 / 4} \frac{X}{\theta_{w}} \\
& \overline{N u}=G r^{1 / 4} \int_{0}^{1} \frac{d X}{\theta_{w}}
\end{aligned}
$$

Local and average Sherwood numbers in non dimensional form are 


$$
\begin{aligned}
& S h_{X}=G r^{1 / 4} \frac{X}{C_{w}} \\
& \overline{S h}=G r^{1 / 4} \int_{0}^{1} \frac{d X}{C_{w}}
\end{aligned}
$$

\section{NUMERICAL TECHNIQUE}

In order to solve the unsteady, non-linear, coupled Eqs. (10) to (13), under the boundary conditions (14), an implicit finite difference scheme of Crank-Nicolson type has been employed. The finite difference equations corresponding to Eqs. (10) to (13) are as follows

$$
\begin{aligned}
& {\left[\frac{U_{i, j}^{n+1}-U_{i-1, j}^{n+1}+U_{i, j}^{n}-U_{i-1, j}^{n}+U_{i, j-1}^{n+1}-U_{i-1, j-1}^{n+1}+U_{i, j-1}^{n}-U_{i-1, j-1}^{n}}{4 \Delta X}\right]} \\
& +\left[\frac{V_{i, j}^{n+1}-V_{i, j-1}^{n+1}+V_{i, j}^{n}-V_{i, j-1}^{n}}{2 \Delta X}\right]=0 \\
& {\left[\frac{U_{i, j}^{n+1}-U_{i, j}^{n}}{\Delta t}\right]+U_{i, j}^{n}\left[\frac{U_{i, j}^{n+1}-U_{i-1, j}^{n+1}+U_{i, j}^{n}-U_{i-1, j}^{n}}{2 \Delta X}\right]} \\
& +V_{i, j}^{n}\left[\frac{U_{i, j+1}^{n+1}-U_{i, j-1}^{n+1}+U_{i, j+1}^{n}-U_{i, j-1}^{n}}{4 \Delta Y}\right]= \\
& {\left[\frac{U_{i, j-1}^{n+1}-2 U_{i, j}^{n+1}+U_{i, j+1}^{n+1}+U_{i, j-1}^{n}-2 U_{i, j}^{n}+U_{i, j+1}^{n}}{2(\Delta Y)^{2}}\right]} \\
& +G r^{-1 / 4}\left[\frac{T_{i, j}^{n+1}+T_{i, j}^{n}}{2}\right]+N\left[\frac{C_{i, j}^{n+1}+C_{i, j}^{n}}{2}\right] \\
& -M\left[\frac{U_{i, j}^{n+1}+U_{i, j}^{n}}{2}\right] \\
& {\left[\frac{T_{i, j}^{n+1}-T_{i, j}^{n}}{\Delta t}\right]+U_{i, j}^{n}\left[\frac{T_{i, j}^{n+1}-T_{i-1, j}^{n+1}+T_{i, j}^{n}-T_{i-1, j}^{n}}{2 \Delta X}\right]} \\
& +V_{i, j}^{n}\left[\frac{T_{i . j+1}^{n+1}-T_{i, j-1}^{n+1}+T_{i, j+1}^{n}-T_{i . j-1}^{n}}{4 \Delta Y}\right]=\frac{1}{\operatorname{Pr}}\left[1+\frac{4}{3 F}\right] \\
& {\left[\frac{T_{i, j-1}^{n+1}-2 T_{i, j}^{n+1}+T_{i, j+1}^{n+1}+T_{i, j-1}^{n}-2 T_{i, j}^{n}+T_{i, j+1}^{n}}{2(\Delta Y)^{2}}\right]} \\
& +E c G r^{1 / 4}\left[\frac{U_{i, j+1}^{n}-U_{i, j}^{n}}{\Delta Y}\right]^{2} \\
& {\left[\frac{C_{i, j}^{n+1}-C_{i, j}^{n}}{\Delta t}\right]+U_{i, j}^{n}\left[\frac{C_{i, j}^{n+i}-C_{i-1, j}^{n+1}+C_{i, j}^{n}-C_{i-1, j}^{n}}{2 \Delta X}\right]} \\
& +V_{i, j}^{n}\left[\frac{C_{i, j+1}^{n+1}-C_{i, j-1}^{n+1}+C_{i, j+1}^{n}-C_{i, j-1}^{n}}{4 \Delta Y}\right]= \\
& \frac{1}{S c}\left[\frac{C_{i, j-1}^{n+1}-2 C_{i, j}^{n+1}+C_{i, j+1}^{n+1}+C_{i, j-1}^{n}-2 C_{i, j}^{n}+C_{i, j+1}^{n}}{2(\Delta Y)^{2}}\right]
\end{aligned}
$$

The boundary condition at $\mathrm{Y}=0$ for the temperature in the finite difference form is

$$
\left[\frac{T_{i, 1}^{n+1}-T_{i,-1}^{n+1}+T_{i, 1}^{n}-T_{i,-1}^{n}}{4 \Delta Y}\right]=-1
$$

At $Y=0$ (i.e. $j=0)$ Eq. (23) becomes

$$
\begin{aligned}
& {\left[\frac{T_{i, 0}^{n+1}-T_{i, 0}^{n}}{\Delta t}\right]+U_{i, 0}^{n}\left[\frac{T_{i, 0}^{n+1}-T_{i-1,0}^{n+1}+T_{i, 0}^{n}-T_{i-1,0}^{n}}{2 \Delta X}\right]+} \\
& V_{i, 0}^{n}\left[\frac{T_{i, 1}^{n+1}-T_{i,-1}^{n+1}+T_{i, 1}^{n}-T_{i,-1}^{n}}{4 \Delta Y}\right]= \\
& \frac{1}{\operatorname{Pr}}\left[1+\frac{4}{3 F}\right]\left[\frac{T_{i,-1}^{n+1}-2 T_{i, 0}^{n+1}+T_{i, 1}^{n+1}+T_{i,-1}^{n}-2 T_{i, 0}^{n}+T_{i, 1}^{n}}{2(\Delta Y)^{2}}\right] \\
& +E c G r^{1 / 4}\left[\frac{U_{i, 1}^{n}-U_{i, 0}^{n}}{\Delta Y}\right]^{2}
\end{aligned}
$$

After eliminating $T_{i,-1}^{n+1}+T_{i,-1}^{n} \quad$ using Eq. (25), Eq. (26) reduces to the form

$$
\begin{aligned}
& {\left[\frac{T_{i, 0}^{n+1}-T_{i, 0}^{n}}{\Delta t}\right]+U_{i, 0}^{n}\left[\frac{T_{i, 0}^{n+1}-T_{i-1,0}^{n+1}+T_{i, 0}^{n}-T_{i-1,0}^{n}}{2 \Delta X}\right]=} \\
& \frac{1}{\operatorname{Pr}}\left[1+\frac{4}{3 F}\right]\left[\frac{T_{i, 1}^{n+1}-T_{i, 0}^{n+1}+T_{i, 1}^{n}-T_{i, 0}^{n}+2 \Delta Y}{(\Delta Y)^{2}}\right] \\
& +E c G r^{1 / 4}\left[\frac{U_{i, 1}^{n}-U_{i, 0}^{n}}{\Delta Y}\right]^{2}
\end{aligned}
$$

The boundary condition at $\mathrm{Y}=0$ for the concentration in the finite difference form is

$$
\left[\frac{C_{l, 1}^{n+1}-C_{i,-1}^{n+1}+C_{i, 1}^{n}-C_{i,-1}^{n}}{4 \Delta Y}\right]=-1
$$

At $Y=0$ (i.e. j=0), Eq. (24) becomes

$$
\begin{aligned}
& {\left[\frac{C_{i, 0}^{n+1}-C_{i, 0}^{n}}{\Delta t}\right]+U_{i, 0}^{n}\left[\frac{C_{i, 0}^{n+1}-C_{i-1,0}^{n+1}+C_{i, 0}^{n}-C_{i-1,0}^{n}}{2 \Delta X}\right]} \\
& +V_{i, 0}^{n}\left[\frac{C_{i, 1}^{n+1}-C_{i,-1}^{n+1}+C_{i, 1}^{n}-C_{i,-1}^{n}}{4 \Delta Y}\right]= \\
& \frac{1}{S c}\left[\frac{C_{i,-1}^{n+1}-2 C_{i, 0}^{n+1}+C_{i, 1}^{n+1}+C_{i,-1}^{n}-2 C_{i, 0}^{n}+C_{i, 1}^{n}}{2(\Delta Y)^{2}}\right]
\end{aligned}
$$

After eliminating $C_{i,-1}^{n+1}+C_{i,-1}^{n}$ using Eq. (28), Eq. (29) reduces to the form

$$
\begin{aligned}
& {\left[\frac{C_{i, 0}^{n+1}-C_{i, 0}^{n}}{\Delta t}\right]+U_{i, 0}^{n}\left[\frac{C_{i, 0}^{n+1}-C_{i-1,0}^{n+1}+C_{i, 0}^{n}-C_{i-1,0}^{n}}{2 \Delta X}\right]} \\
& =\frac{1}{S c}\left[\frac{C_{i, 1}^{n+1}-C_{i, 0}^{n+1}+C_{i, 1}^{n}-C_{i, 0}^{n}+2 \Delta Y}{(\Delta Y)^{2}}\right]
\end{aligned}
$$

The region of integration is considered as a rectangle with sides $X_{\max }(=1)$ and $Y_{\max }(=14)$, where $Y_{\max }$ corresponds to $Y=\infty$, which lies very well outside the momentum, energy and concentration boundary layers. The maximum of $\mathrm{Y}$ was chosen as 14 after some preliminary investigation. So that the last two of the boundary conditions of Eq. (14) are satisfied. Here, the subscription $\mathrm{i}$ - designates the grid point along the $\mathrm{X}$ - 
direction, $\mathrm{j}$-along the $\mathrm{Y}$-direction and the superscript $\mathrm{n}$ along the t- direction. An approximate mesh sizes considered for the calculation is $\Delta X=0.05, \Delta Y=0.25$ and the time step $\Delta t=0.01$. During any one time step, the coefficient $U_{i, j}^{n}$ and $V_{i, j}^{n}$ appearing in the difference equation are treated as constants. The values of $\mathrm{C}, \mathrm{T}, \mathrm{U}$, and $\mathrm{V}$ at time level $(\mathrm{n}+1)$ using the known values at previous time level (n) are calculated as follows.

The finite difference Eqs. (30) and (28) at every interned nodal point on a particular i- level constitute a tridiagonal system of equation. Such a system of equations is solved by using Thomas algorithm as discussed in Carnahan et al. (1969). Thus, the values of $\mathrm{C}$ are known at every internal nodal point on a particular i at $(n+1)^{\text {th }}$ time level. Similarly, the values of T are calculated from Eqs. (27) and (25). Using the values of $C$ and $T$ at $(n+1)^{\text {th }}$ time level in Eq. (22), the values of $U$ at $(n+1)^{\text {th }}$ time level are found in similar manner. Then the values of $\mathrm{V}$ are calculated explicitly using the Eq. (21) at every nodal joint at particular ilevel at $(\mathrm{n}+1)^{\text {th }}$ time level. This process is respected for various $\mathrm{i}$ - levels, thus the values of $\mathrm{C}, \mathrm{T}, \mathrm{U}$ and $\mathrm{V}$ are known at all grid points in the rectangular region at $(\mathrm{n}+1)^{\text {th }}$ time level. Computations are carried out until the steady state is reached. The Steady state solution is assumed to have been reached, when the absolute difference between the values of $\mathrm{U}$ as well as temperature $\mathrm{T}$ and concentration $\mathrm{C}$ at two consecutive time steeps are less than $10^{-5}$ at all grid points.

After experimenting with few sets of mess sizes, they have been fixed at the level $\Delta X=0.05, \Delta Y=0.25$ and the time step $\Delta t=0.01$, in this case, special mesh sizes are reduced by $50 \%$ in one direction, and then in both direction, and the result are compared. It is observed that when mesh size is reduced by $50 \%$ in $\mathrm{X}$ - direction and $\mathrm{Y}$ direction, the result differ in the fourth decimal places. The computer takes more time to compute, if the size of the time step is small. Hence the above mentioned sizes have been considered as appropriate mesh sizes for calculation.

The local truncation error is $O\left(\Delta t^{2}+\Delta Y^{2}+\Delta X\right)$ and it tends to zero as $\Delta t, \Delta Y$ and $\Delta X$ tend to zero. Hence the scheme is compatible. The stability and compatibility insure convergence.

The derivatives involved in Eqs. (15) to (20) are evaluated using five point approximation formula and then the integrals are evaluated using Newton - Cotes closed integration formula.

\section{RESULTS AND DISCUSSIONS}

Representative set of numerical results shown graphically in Figs. 1 to 15, illustrate the influence of physical parameters Viz., radiation parameter F, Grashof number Gr, Buoyancy ratio parameter N, Eckert number Ec, Schmidt number Sc, Magnetic parameter M, Prandtl number $\operatorname{Pr}$ on velocity, temperature and concentration, skin-friction, Nusselt and Sherwood number.
In order to check the accuracy of our numerical results, the present study is compared with the available theoretical solution of Gokhale and Samman (2003) in Fig. 1a, and they are found to be in good agreement.

For different values of the radiation parameter $F$, the transient velocity and temperature profiles are plotted in Fig. 1b and 1c. $F=\frac{k_{e} k}{4 \sigma_{s} T_{\infty}^{\prime 3}}$ and this defines the ratio of thermal conduction contribution relative to the thermal radiation. For radiative heat transfer dominance in the boundary layer regime, $\mathrm{F} \rightarrow 0$. For finite values of $\mathrm{F}$ there will be a simultaneous presence of thermal conduction and radiative transfer contribution. For $\mathrm{F}=1$ both modes will contribute equally. For $\mathrm{F} \rightarrow \infty$, in Eq. (12), the term $4 / 3 \mathrm{~F} \rightarrow 0$ and the energy conservation equation reduces to the convectional unsteady conduction-convection equation with dissipation i.e.

$$
\begin{aligned}
\frac{\partial T}{\partial t}+U \frac{\partial T}{\partial X}+ & V \frac{\partial T}{\partial Y}=\frac{1}{\operatorname{Pr}} \frac{\partial^{2} T}{\partial Y^{2}} \\
& +G r^{1 / 4} E c\left(\frac{\partial U}{\partial Y}\right)^{2}
\end{aligned}
$$

An increase in $\mathrm{F}$ from 0 (total thermal radiation dominance) through $3.0,5.0$ to 10.0 , causes a significant decrease in velocity with distance into the boundary layer i.e. decelerates the flow. Velocities in all cases ascend from the plate surface, peak close to the wall and then decay smoothly to zero in the free stream. We also note that with increasing values of $F$ the time taken to attain the steady state is reduced. Thermal radiation flux therefore has a de-stabilizing effect on the transient flow regime. This is important in polymeric and other industrial flow processes since it shows that the presence of thermal radiation while decreasing temperature, will affect flow control from the plate surface into the boundary layer regime. As expected, temperature values are also significantly reduced with an increase in $\mathrm{F}$ as there is a progressive decrease in thermal radiation contribution accompanying this. All profiles are monotonic decay from the wall to the free stream.

The effects of the viscous dissipation parameter i.e. Eckert number Ec on the transient velocity and temperature are shown in Figs. $2 a$ and $2 b$, the time taken to reach the steady state increase in Eckert number Ec. Also greater viscous dissipative heat causes rise in the temperature as well as the velocity.

Figures $3 \mathrm{a}$ and $3 \mathrm{~b}$ present transient velocity and temperature profiles in the boundary layer for various values of $\mathrm{Gr}$, respectively. Increasing the value of $\mathrm{Gr}$ have the tendency to induce more flow in the boundary layer due to the effect of thermal buoyancy for small buoyancy effects $(\mathrm{Gr}=2)$, The maximum flow velocity occurs at the plate. However, as the buoyancy effects gets a relatively large, a distinctive peak in the velocity profiles, occurs in the fluid adjacent to the wall and this peak more distinctive as $\mathrm{Gr}$ increase further. Along with this flow behaviors, the temperature reduce as $\mathrm{Gr}$ 
increases causing the fluid temperature to reduce at every point other than that the wall. These flow and thermal behaviors are depicted by the respective increases and decrease in the velocity temperature fields as Gr increases shown in Figs $3 a$ and $3 b$.

Figures $4 \mathrm{a}$ and $4 \mathrm{~b}$ had shown the effect of $\operatorname{Pr}$ on the transient velocity and temperature profiles. The time taken to reach the steady state increases with increasing Pr. From Fig. 4b, it is observed that as increase in the Prandtl number results a decrease of the thermal boundary layer thickness and in general lower average temperature within the boundary layer. The reason is that smaller values of $\mathrm{Pr}$ are equivalent to increase in the thermal conductivity of the fluid and therefore heat is able to diffuse away from the heated surface more rapidly for higher values of Pr. Hence in the case of smaller Prandtl numbers as thermal boundary layer is thicker and the heat transfer is reduced.

Figures $5 \mathrm{a}$ and $5 \mathrm{~b}$ illustrate the influence of the Schmidt number Sc on the transient velocity and concentration. As Sc increases the concentration decreases. The cause the concentration buoyancy effects to decrease yielding a reduction in the fluid velocity. The reduction in the velocity and concentration profiles is accompanied by simultaneous reductions in velocity and concentration boundary layer. These behaviors are clear from Figs. $5 \mathrm{a}$ and $5 \mathrm{~b}$ also the time required to reach the steady state increases with the increase in Sc.

For various values of the magnetic parameter $M$ the velocity profiles are plotted in Fig. 6 . The influence of the magnetic parameter $\mathrm{M}$ on the velocity profiles is an expected. As M increase the Lorentz force which oppose the flow also increases and leads to enhanced deceleration of the flow this result qualitatively agrees with the expectations, since the magnetic filed exact a retarding force on the free convective flow the obvious from the decrease in the velocity profiles in Fig. 6.

The effect of buoyancy ratio parameter $\mathrm{N}$ on the steady state velocity, temperature and concentration profiles is shown in Figs. 7 to 9 it is formed from these figures that when there is opposing buoyancy force the velocity is less but the temperature and the concentration are more compared to that in the presence of aiding buoyancy force the velocity is also found to increase as the aiding buoyancy force increases. But both the temperature and concentration decrease as aiding buoyancy force increases.

Figures 10 and 11 illustrate the effects of M, F, Sc, Ec and $\mathrm{N}$ on the local and Average skin friction respectively. Both the local and average skin friction is found to decrease with an increase in M, F \& Sc. Increase in Ec and $\mathrm{N}$ leads to an increase in both local and average skin friction.

Figures 12 and 13 show the effects of radiation parameter F, Eckert number and buoyancy ration parameter $\mathrm{N}$ on the local and average Nusselt numbers respectively. It is observe that the local and average Nusselt numbers increase with the increase in F, Ec and $\mathrm{N}$.
Figures 14 and 15 display the effect of Sc on the local and average Sherwood number respectively. We can easily see that as Sc increase the local and average Sherwood number increase.

\section{REFERENCES}

Abd El- Naby, M.A., M.E.E. Elbarbary and Y.A. Nader (2003). Finite difference solution of radiation effects on free convection flow over a vertical plate with variable surface temperature. J. Appl. Math. 2, 65-86.

Aboeldahab, E.M. and E.M.E. Elbarbary (2001). Hall current effect on magneto-hydrodynamic free convective flow past a semi-infinite vertical plate with mass transfer. Int. J. Eng. Sci. 39, 1641-1652.

Brewster, M.Q. (1992). Thermal radiative transfer and Properties. John Wiley \& Sons, Inc., New York.

Callahan, G.D. and W.J. Manner (1976). Transient free convection with mass transfer on an isothermal vertical flat plate. Int. J. Heat Mass Transfer 19, 165-174.

Carnahan, B., H.A. Luther, J.O. Wilkes (1969). Applied Numerical Methods. John Wiley, New York.

Chamkha, A.J., H.S. Takhar and V.M. Soundalgekar (2001). Radiation effects on free convection flow past a semi-infinite vertical plate with mass transfer. Chem. Engg. J 84, 335-342.

Chen, C.H. (2004). Heat and mass transfer in MHD flow by natural convection from a permeable inclined surface with variable wall temperature and concentration. Acta. Mech. 172, 219-235.

Elbashbeshy, E.M.A. (1997). Heat and mass transfer along a vertical plate with variable surface temperature and concentration in the presence of magnetic field. Int. J. Engg. Sci. 34, 515-522.

Ganesan, P. and P. Loganadan (2002). Radiation and mass transfer effects on flow of an incompressible viscous fluid past a moving cylinder. Int. J. Heat Mass Transfer 45, 4281-4288.

Ganesan, P. and H.P. Rani (2000). Unsteady free convection MHD flow past a vertical cylinder with mass transfer. Int. J. Ther. Sci. 39, 265-272.

Gebhart, B. (1962). Effect of viscous dissipation in natural convection. J. Fluid Mech. 14, 2, 225-232.

Gebhart, B. and J. Mollendraf (1969). Viscous dissipation in external natural convection flows. $J$. Fluid. Mech. 38, 97-107.

Gebhart, B. and L. Pera (1971). The nature of vertical natural convection flows resulting from the combined buoyancy effects of thermal and mass diffusion. Int. J. Heat Mass Transfer 14, 20252050. 
Gebhart, B. (1961). Transient natural convection from vertical elements. J. Heat Transfer 83C, 61-70.

Gokhale, M.Y. and F.M. Al Samman (2003). Effects of mass transfer on the transient free convection flow of a dissipative fluid along a semi-infinite vertical plate with constant heat flux. Int. J. Heat and Mass Transfer 46, 6, 999-1011.

Israel-Cookey, C., A. Ogulu and V.B. Omubo-Pepple (2003). Influence of viscous dissipation on unsteady MHD free convection flow past an infinite heated vertical plate in porous medium with time-dependent suction. Int. J. Heat mass Transfer 46, 2305-2311.

Mathers, W.G., A.J. Madden and E.L. Piret (1956). Simultaneous heat and mass transfer in free convection. India. Engg. Chem. 49, 961-968.

Michiyochi, I., I. Takahashi and A. Serizawa (1976). Natural convection heat transfer from a horizontal circular cylinder to mercury under a magnetic field. Int. J. Heat Mass Transfer 19, 1021-1029.

Ostrach, S. (1953). An analysis of laminar free convection flow and heat transfer along a flat plate parallel to the direction of the generating body force. NACA report TR-1111, 63-79.

Pohlhausen, E. (1921). Der Warmeaustrausch Zwischen Festen Korpen and Flussigkeiten mit Kleiner Reibung under kleiner Warmeleitung. ZAMM 1, 115-121.

Riley, N. (1976). Magnetohydrodynamic free convection about a semi-infinite vertical plate in strong cross-field. J. Appl. Math. Phys. (ZAMP) 27, 621-631.

Siegel, R. (1958). Transient free convection from a vertical flat plate. J. Heat Transfer 80, 347-359.

Somers, E.V. (1956). Theoretical considerations of combined thermal and mass transfer from vertical flat plate. J. Appl. Mech. 23, 295-301.

Soundalgekar, V.M. (1972). Viscous dissipation effects on unsteady free convective flow past an infinite, vertical porous plate with constant suction. Int. J. Heat Mass Transfer 15, 6, 1253-1261.

Soundalgekar, V.M. and P. Ganesan (1981). FiniteDifference analysis of transient free convection with mass transfer on an isothermal vertical flat plate. Int. J. Eng. Sci. 19, 757-770.

Soundalgekar, V.M. and P.D. Wavre (1977). Unsteady free convection flow past an infinite vertical plate with constant suction and mass transfer. Int. J. Heat mass transfer 19, 1363-1373.
Sparrow, E.M. and R.D. Cess (1961). The effect of a magnetic field on free convection heat transfer. Int. J. Heat Mass Transfer 4, 267-274.

Takhar, H.S., P. Ganesan, K. Ekambavahar and V.M. Soundalgekar (1997). Transient free convection past a semi-infinite vertical plate with variable surface temperature. Int. J. Numerical Methods, Heat Fluid Flow 7, 4, 280-296.

Takhar, H.S., R.S.R. Gorla and V.M. Soundalgekar (1996). Radiation effects on MHD free convection flow of a radiation gas past a semi-infinite vertical plate. Int. J. Numerical Methods Heat Fluid Flow $6,2,77-83$.

Vajravelu, K. and J. Nayfeh (1992). Hydrodynamics convection at a cone and a wedge. Int. Commun. Heat Mass Transfer 19, 701-710.

Watanabe, T. and I. Pop (1994). Thermal boundary layers in magneto hydrodynamic flow over a flat plate in the presence of transverse magnetic field. Acta. Mech. 105, 233-238. 


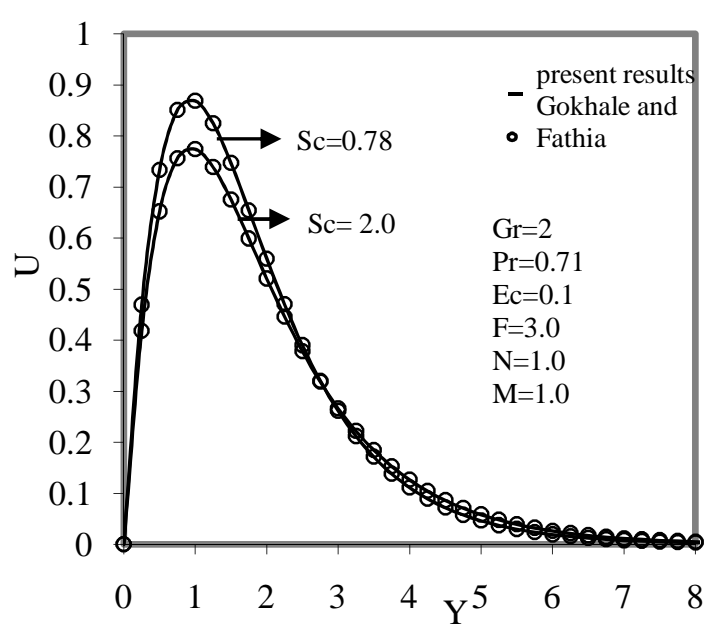

Fig.1a. Comparison of velocity profiles

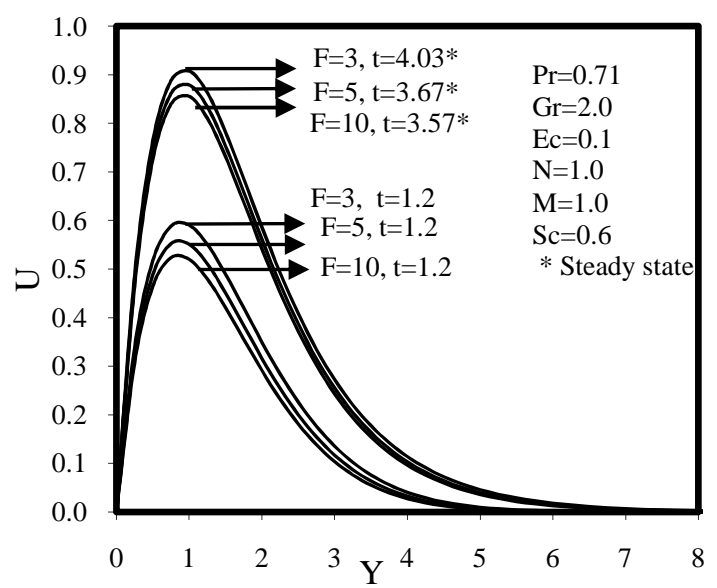

Fig.1b. Effect of radiation on transient velocity profiles.

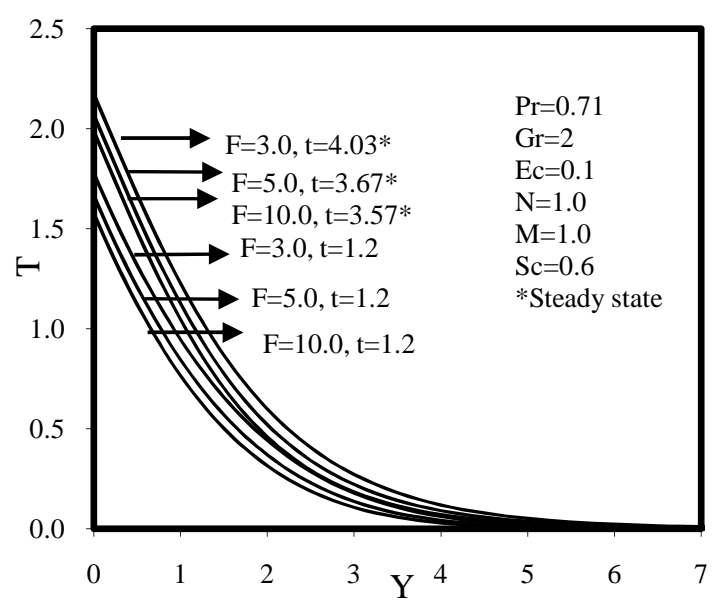

Fig.1c. Effect of Radiation on transient temperature profiles.

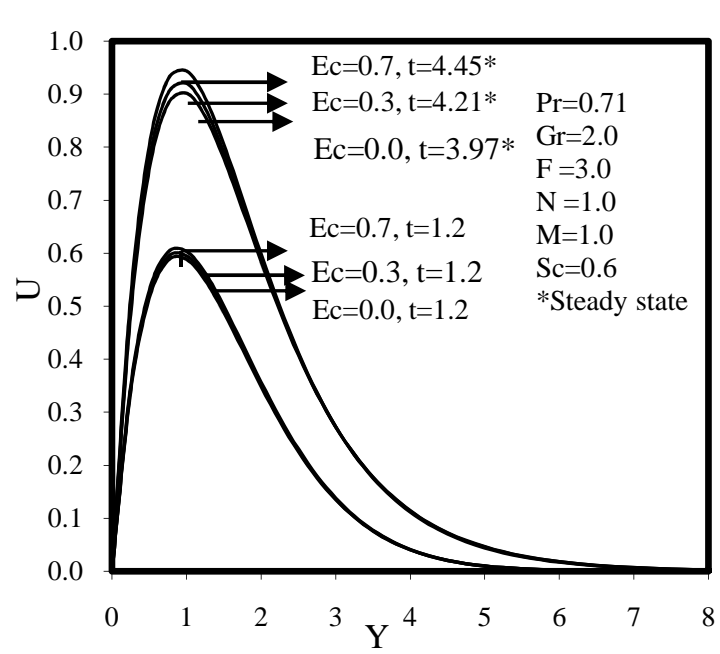

Fig.2a. Effect of Ec on transient velocity profiles.

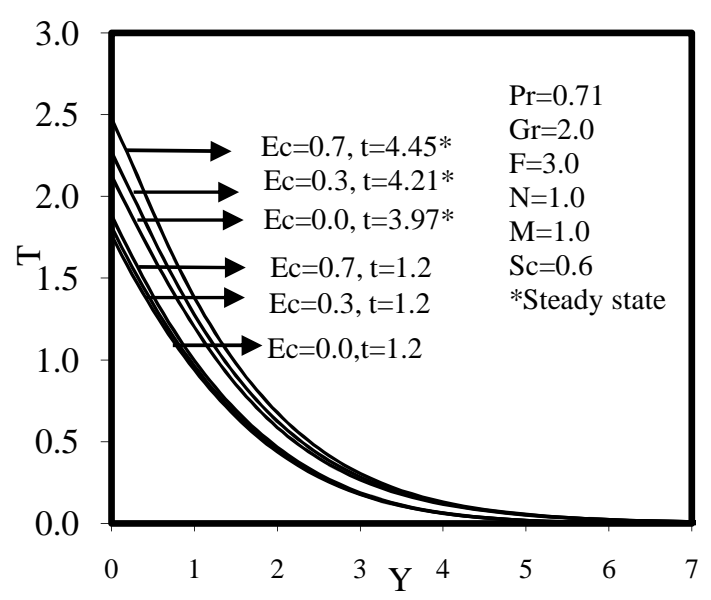

Fig.2b. Effect of Ec on transient temperature profiles.

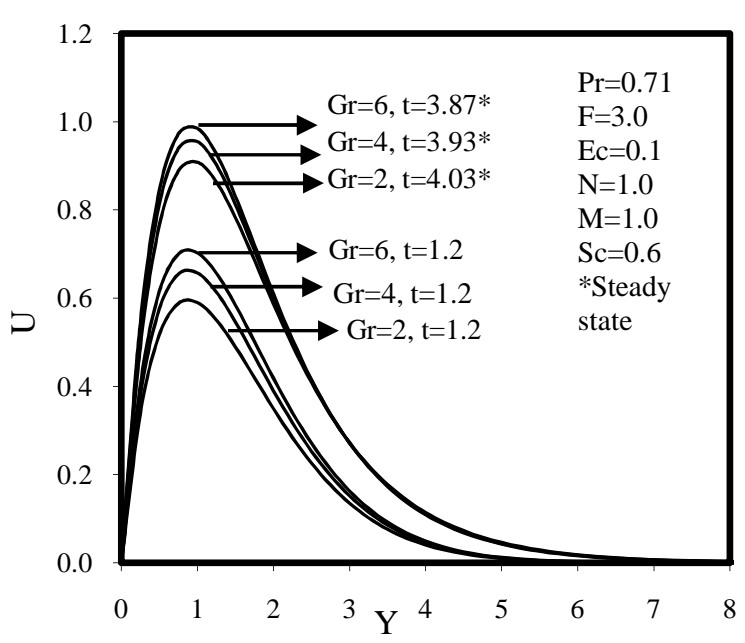

Fig.3a. Effect of Gr on transient velocity profiles 


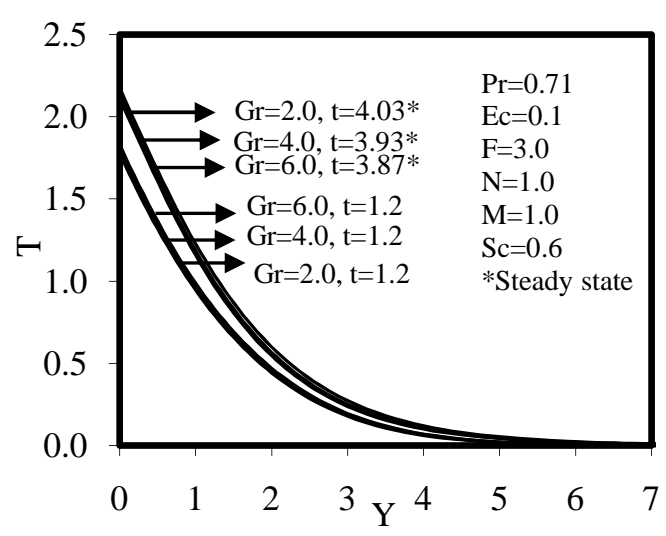

Fig.3b. Effect of Gr on transient temperature profiles

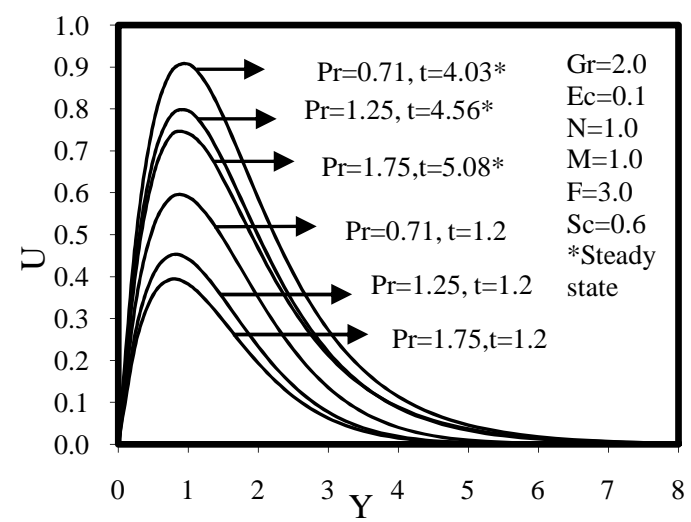

Fig.4a. Effect of Pr on transient velocity profiles

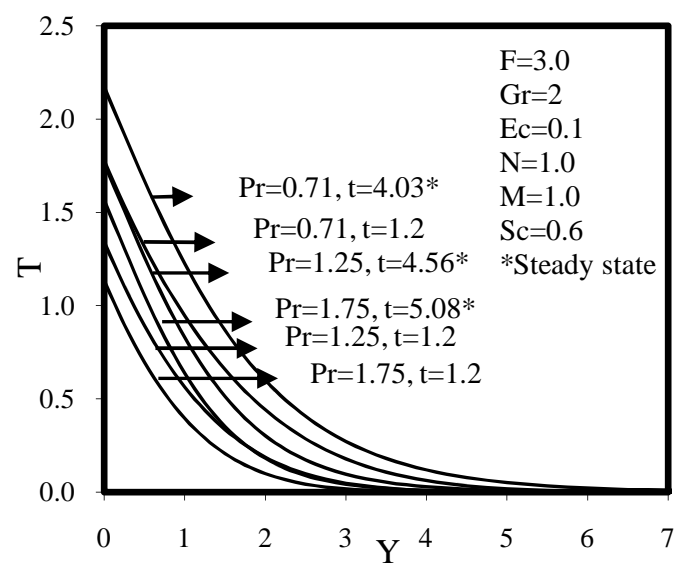

Fig.4b. Effect of Pr on transient temperature profiles

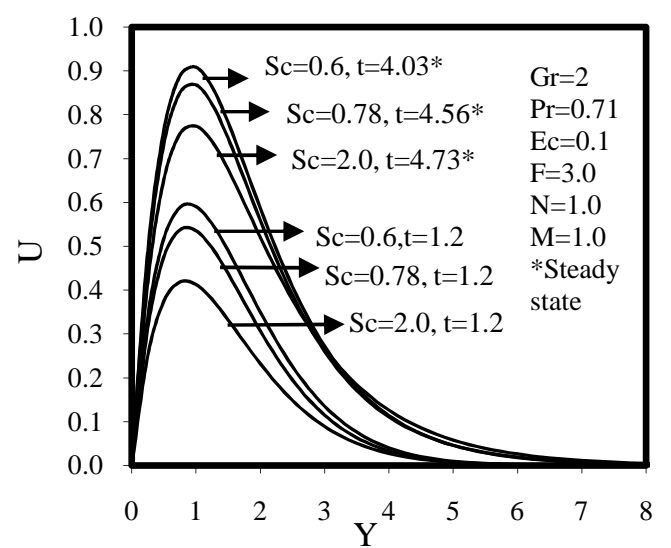

Fig.5a. Effect of Sc on transient velocity profiles

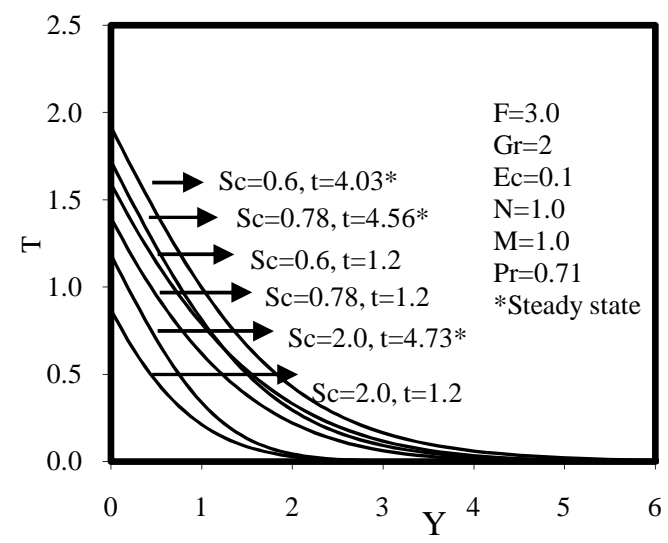

Fig.5b. Effect of Sc on transient concentration profiles

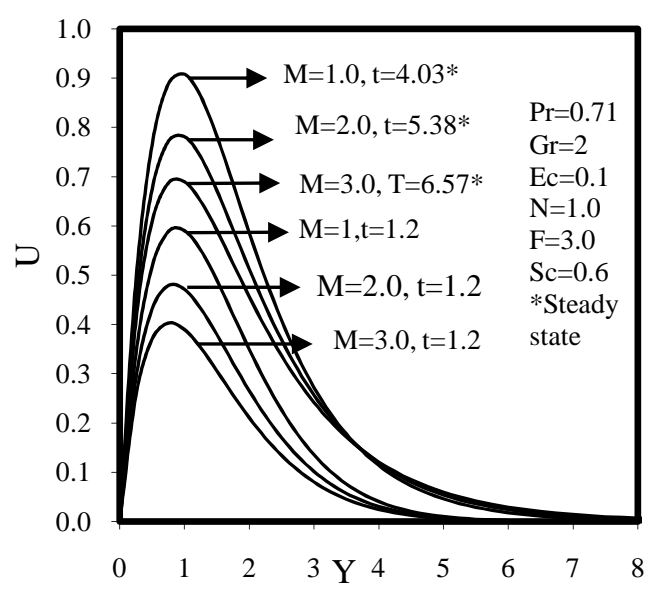

Fig.6. Effect of M on transient velocity 


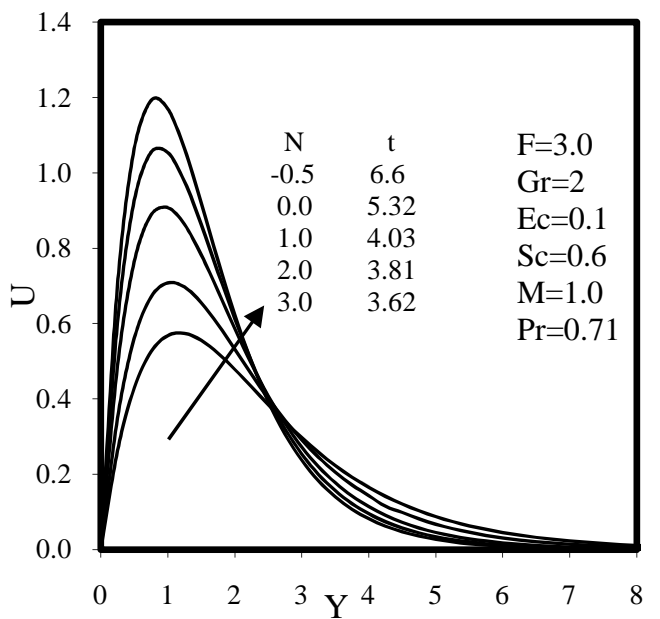

Fig.7. Steady state velocity profiles for different N.

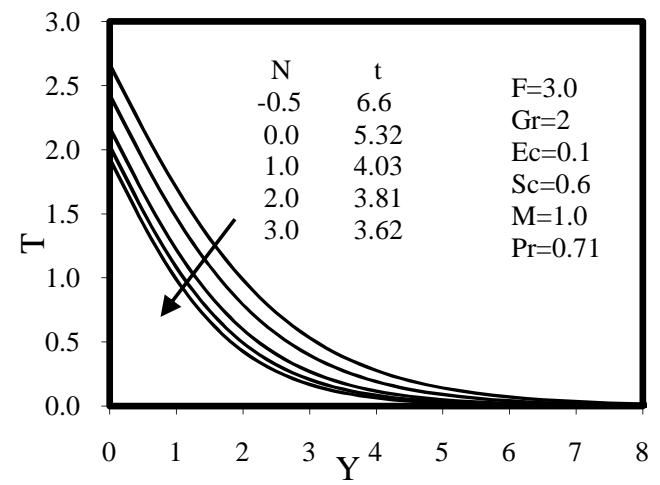

Fig.8. Steady state temperature profiles for different $\mathrm{N}$.

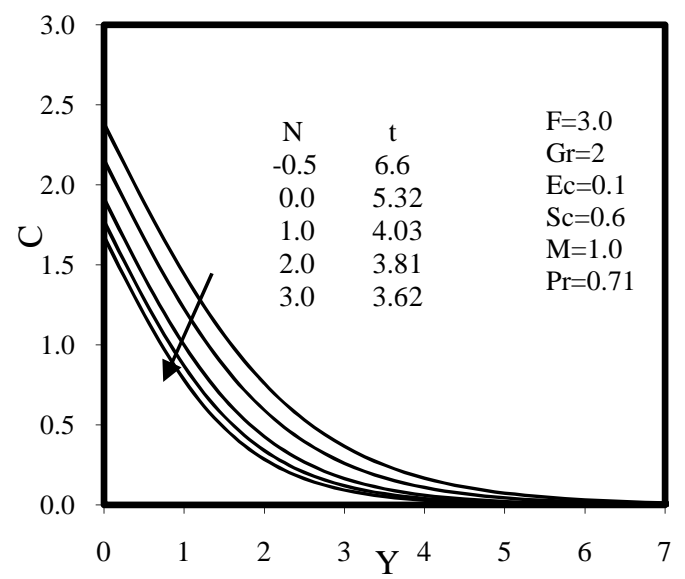

Fig.9. Steady state concentration profiles for different $\mathrm{N}$.

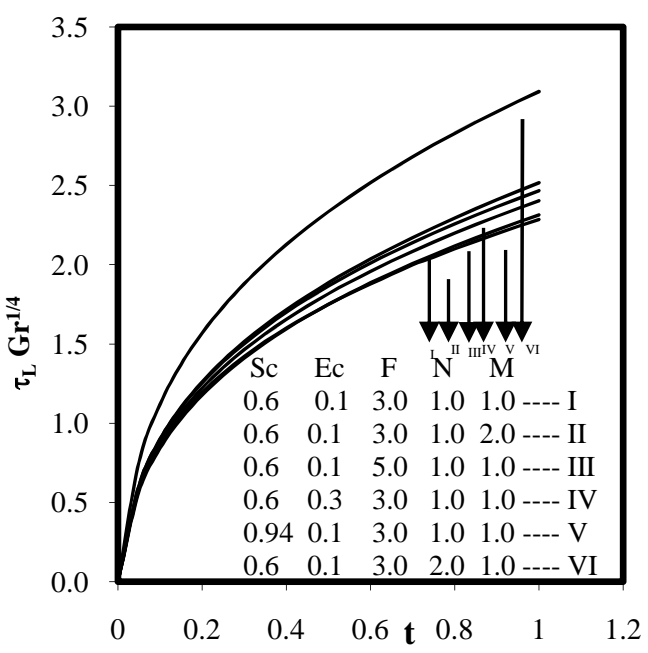

Fig.10. Steady state local skinfriction. $\operatorname{Pr}=0.71$, $\mathrm{Gr}=2.0$.

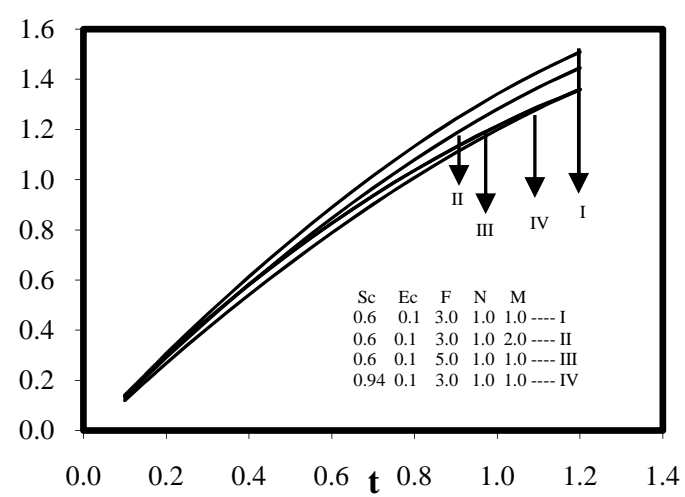

Fig.11. Average skinfriction number. $\operatorname{Pr}=0.71$, $\mathrm{Gr}=2.0, \mathrm{~N}=1.0$.

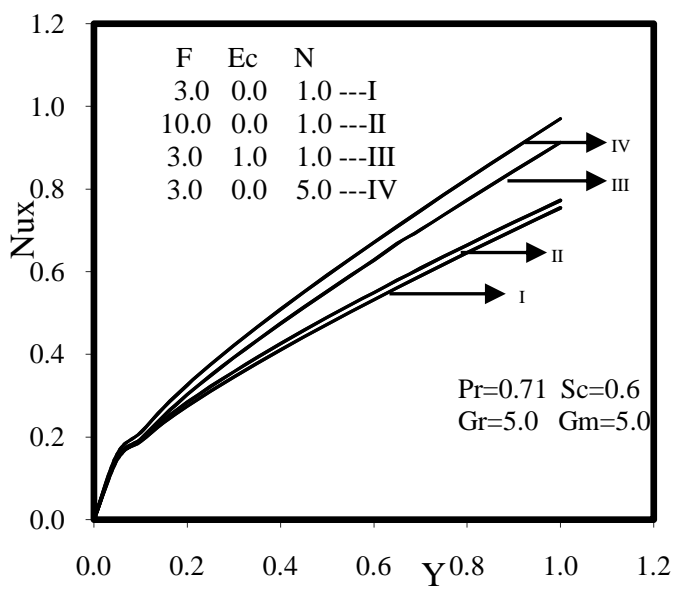

Fig.12. Local Nusselt number. 
B. Vasu et al. / JAFM, Vol. 4, No. 1, pp. 15-26, 2011.

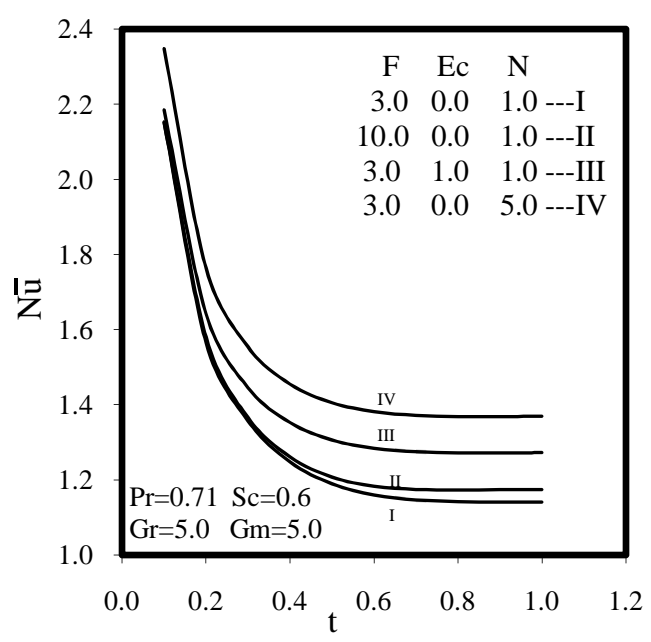

Fig.13. Average Nusselt number.

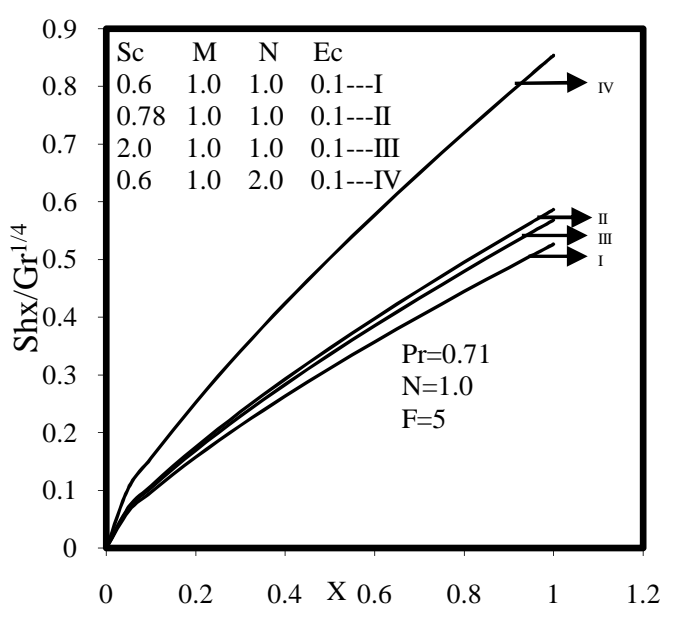

Fig.14. Stady state local sherwood number

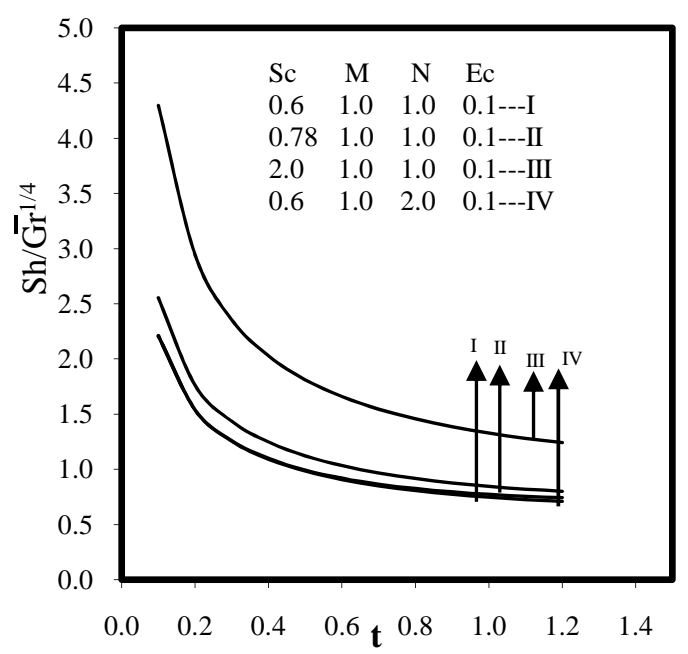

Fig.15. Average sherwood number. $\operatorname{Pr}=0.71$, $\mathrm{Gr}=2.0, \mathrm{~F}=3.0$. 